\title{
Analysis on the Plastic Arts of Oroqen Ethnic Ornaments and Its Inheritance
}

\author{
Zhongfeng $\mathrm{Fu}^{1, *}$ Xiaoli Zhang ${ }^{1}$ \\ ${ }^{1}$ Heihe University, Heihe, Heilongjiang 164300, China \\ *Corresponding author. Email: 33746210@qq.com
}

\begin{abstract}
As one of the ethnic minorities in northern China, the Oroqen nationality still retains the unique characteristics of the traditional nomadic people. This article mainly analyzes the connotation of the Oroqen ethnic ornaments, the materials of dress patterns and its application methods, and demonstrates the inheritance methods and inheritance connotation in the plastic arts of the Oroqen nationality, and explores the application of the formal beauty of decorative plastic art in contemporary art design.
\end{abstract}

Keywords: Oroqen nationality, Pattern, Ornaments, Plastic arts, The analysis of materials.

\section{INTRODUCTION}

For any nation, it has its own unique dress patterns. A nation's dress patterns are not only the unique aesthetic representatives, but also show the national spirit and convey the aesthetic psychological characteristics. The symbol is a unique aesthetic form of a nation and represents specific cultural connotation. And the culture and regional content of the nation can be reflected in the simplest and most unique way. China is a country with many nationalities. The cultural connotation and expression forms of different regions are also very different. Through the analysis of the culture of different regions, it is found that there are differences among the cultural connotations, and the decorative style of clothing can be said to be various. By analyzing the unique artistic patterns of Oroqen people, the unique characteristics of Oroqen nationality will be clear.

\section{CULTURAL CONNOTATION OF OROQEN ETHNIC ORNAMENTS}

The Oroqen nationality has its unique customs, aesthetic characteristics, clothing patterns, aesthetic ideas, aesthetic taste and so on, which is the external performance and internal ideological

*Fund: This paper is supported by the phased achievements of Heilongjiang Philosophy and Social Science Research Project (19YSE355) and phased research results of "Heilongjiang Basic Scientific Research Project" (2018-KYYWF-1274). transmission. It is different from the characters, but it has the same function with the characters. They both inherit the national culture and ideological connation of the Oroqen nationality. Therefore, the analysis of clothing patterns of Oroqen nationality also reflects the unique ethnic plastic arts.

\section{ANALYSIS ON THE MATERIALS OF OROQEN ETHNIC CLOTHING ORNAMENTS}

The materials of patterns and ornaments of Oroqen ethnic costumes can be divided into three categories: white birch bark, fishskin and hide.

\subsection{White Birch Bark}

When analyzing the clothing patterns of Oroqen nationality, the living environment and state should be considered first. The Oroqen people live in deciduous arbor forest, which has strong vitality and is widely distributed in Daxing'anling and Xiaoxing'anling Mountains. White birch is the most common tree in the living environment of Oroqen nationality. Compared with other trees, white birch bark has many advantages, one of which is its flexibility. White birch bark is easy to carry and can grow in a relatively humid environment. People can make white birch bark into a variety of different appliances. For example, it can be used in the production of utensils and daily preservation. White birch bark is highly welcomed by Oroqen people, 
not only because the utensils made are easy to carry, but also are very durable. White birch bark has become a part of the clothing patterns. Sometimes people use it as clothing patterns, decorative patterns, such as robes. And it is also widely used in daily life. For example, the common cup and bowl can be used to store food and water. White birch bark is also used in architecture, such as tents. White birch bark is also used in decorations. For example, it is used in the common mosaic paintings of Oroqen people and the clothing patterns. This material is unique and has a strong sense of mystery.

\subsection{Fishskin}

The fishskin can also be seen in the clothing patterns. Fishskin culture can be said to be one of the characteristics culture of Oroqen nationality. In many cases, it exists in the area above north latitude 45 degrees. Many ethnic groups have the culture on fishskin clothing, and it is true for the Oroqen nationality. This culture has been passed down by them. However, the traditional fishskin processing is relatively complex. The fishskin can be used to make a variety of different clothing, such as gloves, leggings, coats, and can also be made into a variety of different forms of clothing, both warm and beautiful. However, this process is very complex, the cost is relatively high, and there are great limitations, which makes the current fishskin gradually replaced by other materials. Even among the Oroqen people, the traditional technology of fishskin production has not been inherited well.

\subsection{Hide}

By analyzing the whole costume of the Oroqen nationality, it can be found that there are a lot of hide materials, such as the fur of roe deer. Many Oroqen people's coats are made of roe deer's fur. What's more, people will wear leather boots made of roe deer's fur, which profoundly reflects the hunting economic characteristics of Oroqen people and Shaman culture involved in traditional culture. In the production of hide materials, the fur of male roe deer is selected in summer. In order to obtain beautiful appearance, the fur of male roe deer will be embroidered with various patterns. Also, hide materials are used to make daily necessities. For example, the luxurious mattress made of the fur of 13 roe deer legs shows the beauty of simplicity, and it is true for the double sheet and quilt made of fur of roe deer. These ornaments are very beautiful, and the cloud patterns also show the unique embroidery beauty of Oroqen nationality. The sleeping bag made of roe deer's fur also shows the unique connotation of Oroqen clothing patterns.

In the process of making costumes for the Oroqen people, the left patterns and right patterns are strictly symmetrical. Even for the decoration on the cuffs and the decorative patterns on the waist are strictly symmetrical. Most of the patterns include the sun, moon, stars, mountains and rivers. The clothing color is rich, and what it wants to convey is the infinite yearning of the Oroqen people for life, the worship of nature and the expectation for social development.

\section{THE APPLICATION OF FORMAL BEAUTY OF PLASTIC ARTS OF OROQEN ETHNIC CLOTHING PATTERNS}

\subsection{Formal Beauty Formed by Material Improvement}

At present, in order to make the Oroqen nationality's clothing patterns and decorative patterns be thoroughly applied in real life, it is necessary to make the improved and bionic design. The so-called improved design is based on the consumer's understanding of these contents and the analysis after use. Each different product has undergone long-term historical improvement, but there is still a certain difference in use from people at this stage. Whether it is the experience of use or the idea when using it, it can show people's different ideas about the use of these items. For example, in the original design process, the preciousness of hide materials is not considered. Also, it is currently impossible to make a large number of quilts with the fur of roe deers. For this reason, it must be considered whether hide can be improved if they are selected for production, and whether they can be artificially copied. People can only use the patterns of hide, but not choose to kill a large number of animals. Bionic design also occupies a very important position in the current product design, which is the core of product design. Bionics and design are closely related. It can be said that they cannot be separated. Creative inspiration mainly comes from the unique behavior 
characteristics and appearance characteristics of all natural things. With these inspirations and references, creators can break through the traditional concepts and make a new ideological and cultural creativity. The emotion is also reflected in the form, structure, mechanism and color of products, fully showing the unique aesthetic feeling of these products.

\subsection{Formal Beauty Formed Because of Emotional Needs}

In the process of emotional design, the first thing to consider is the emotional appeal of cultural and creative products, which can be divided into three different theoretical levels. People can make the analysis from the simple to the deep, understand the instinctive behavior and reflection of these cultural contents, do a good job in shape design, understand the internal meaning and effect, and make good efforts in self-image design, personal satisfaction and so on. The in-depth emotional design can make the emotion at the three levels corresponding to the design. At the same time, it is necessary to analyze the emotional changes brought about by different materials. The designers can't blindly infuse the existing emotions into the materials.

The plastic arts of Oroqen nationality are very diverse, and the changes in the connotation and shape of costumes involved also show the accumulation formed by the cultural changes of the Oroqen nationality for thousands of years, and it is the unique cultural development at present. Among them, the intangible cultural heritage is the main one. The Oroqen nationality has created a large number of national crafts and traditional national cultural heritage in social production and practice, which are urgently needed to be protected. In arts and crafts, whether it is the beauty of function, technology, material, harmony and form, it can show a nation's unique cultural connotation and unique aesthetic feeling. These contents should be further analyzed to show the unique meaning and unique aesthetic experience of different cultures. Therefore, it is necessary to form an organic integration, which is the highest principle.

For example, the rhododendron dauricum pattern is shown in "Figure 1" below. The rhododendron dauricum pattern is a unique pattern developed by the Oroqen people from azaleas and antlers. The rhododendron dauricum pattern in the Oroqen language means that it is the most beautiful. The rhododendron dauricum pattern symbolizes pure love. It also represents the most beautiful flower in Oroqen language. It is the most common pattern on girls' dowry in Oroqen nationality, expressing the elder's blessing on married girls. It hopes that love is pure and beautiful, and that married life is very lucky and happy, and that husband and wife love each other forever. The common shape is composed of cloud roll pattern and branches and leaves. The pattern formed by the combination of cloud roll and branches and leaves with rhododendron dauricum makes rhododendron dauricum pattern shine brilliantly. People use their own imagination to create a unique rhododendron dauricum pattern. The rhododendron dauricum pattern has also become one of the unique contents of Oroqen people's clothing patterns and plastic arts. Because rhododendron dauricum pattern is the most beautiful pattern in the eyes of Oroqen people, they often embroider or carve it with very bright and beautiful colors, and use black to set off the pattern. Different colors can also be embroidered on the rhododendron dauricum pattern. The common colors are red, tender green, snow-green and sky blue. These colors also form a very sharp contrast with each other, which makes the rhododendron dauricum pattern generous and decent without losing the sense of hierarchy. It forms a very perfect work and makes the rhododendron dauricum pattern a favorite dress pattern of the Oroqen people. In the process of its formation, rhododendron dauricum pattern can also be applied in different places. It not only conveys the minority culture, but also makes the unique implication contained in the minority culture understood by more people.

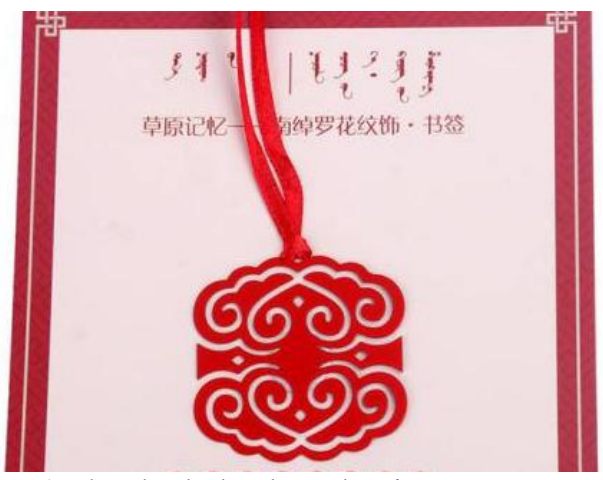

Figure 1 The rhododendron dauricum pattern. 


\subsection{Providing More Innovative Inspiration for Modern Society}

With the unique influence of natural environment and life style, there are also different textures in the handicraft works of Oroqen nationality, reflecting the characteristics of coordination and balance between people and things, characters and nature, people and nature in Oroqen ethnic culture, and also showing the ecology-centered aesthetic concept, as well as people's subjective initiative and creativity. The unique clothing patterns and cultural connotation of Oroqen nationality also show the artistic expression of Oroqen nationality. It can be seen that the local customs, the cultural function of the forest and aesthetic characteristics always follows the three different principles of economy, applicability and beauty. A lot of modeling rules are integrated into the process of artistic creation, and then the works will be more simple and natural, with stronger affinity and more obvious meaning. The Oroqen people show their artistic images, abstract metaphors and symbols incisively and vividly, so that people can understand what they think through symbols in the shortest time. Moreover, the thoughts and feelings, non-utilitarian aesthetic standards, the spiritual pursuit and the pursuit of social and natural objects can be reflected. It can not only improve people's understanding of different objects, but also show its unique artistic decoration effect. At the same time, the unique innovation ability of Oroqen nation can be shown.

\section{CONCLUSION}

To sum up, through the analysis of the unique clothing patterns of Oroqen nationality, people can find the way and connotation of inheritance when promoting cultural heritage. The ethnic clothing culture of Oroqen nationality is a kind of handicraft derived from hunting culture, which is the national intangible cultural heritage. The costumes and utensils represented by hide and birch bark, and the paintings and sculpture with relevant patterns show the unique history of Oroqen nationality. These arts not only need to be displayed in museums and multimedia, but also need to be passed on through the communication between people, so as to make more and more people understand the positive impact of the Oroqen culture on all walks of life.
And then, Oroqen culture will be no longer too high-minded to be popular.

\section{AUTHORS' CONTRIBUTIONS}

Zhongfeng Fu wrote the manuscript, and Xiaoli Zhang contributed to revising and editing.

\section{REFERENCES}

[1] Guo Jianbin, Han Youfeng. The Oroqen Nationality (Survey in Xinsheng Village, Heihe City, Heilongjiang). Yunnan University Press. 2004. (in Chinese)

[2] Wang Bingzhen. Research on the Aesthetic Culture of the Oroqen Nationality. China Social Sciences Press. 2019. (in Chinese)

[3] Compilation Group. A Brief History of the Oroqen Nationality. 2008. (in Chinese)

[4] Guan Xiaoyun, Wang Honggang. A survey of the relics of the Oroqen Shaman Culture. 2010. (in Chinese)

[5] Wang Bingzhen. Research on Aesthetic Culture of Oroqen Nationality [D]. Heilongjiang University. 2014. (in Chinese)

[6] Zhang Huiping. Research on the Traditional Ecological Consciousness of the Oroqen Nationality - Modern Interpretation of Ethnic Forest Culture [D]. Beijing Forestry University. 2018. (in Chinese) 